\title{
The Joint Impact of Achievement Goals and Performance Feedback on Information Giving
}

\author{
P. Marijn Poortvliet \\ Tilburg University \\ Onne Janssen, Nico W. Van Yperen, and Evert Van de Vliert \\ University of Groningen
}

\begin{abstract}
This research examined how performance feedback moderates the effects of individuals' achievement goals on information exchange when carrying out a novel and complex task. Experiment 1 demonstrated that mastery goal individuals who received positive performance feedback gave less modified information about their task performance to their exchange partner relative to both mastery goal individuals who received negative feedback and performance goal individuals (who received either negative or positive feedback). In Experiment 2, we found that relative to performance goals, mastery goals led to a stronger reciprocity orientation and a weaker exploitation orientation. Also, mastery goal individuals provided information of higher quality than performance goal individuals, thereby explaining the observed findings in Experiment 1.
\end{abstract}

Information exchange may be helpful to acquire task-related problem solutions, particularly when people are engaged in carrying out new and complex tasks. However, the ability to give meaningful task-related information to others at a certain point during task execution depends on the performance level one has actually reached at that point. To make an assessment of their current task proficiency, individuals often use feedback information about the effects of their task activities they obtain from the task process itself or from constituents in the task environment. For example, when a coworker asks you how to use a specific software package that you yourself just successfully have learned to use, it is probably easy for you to provide this coworker with useful information. However, if you are still unable to operate the program yourself, it is obviously much harder for you to give your colleague meaningful information and you may therefore decide to invest extra effort in enhancing your skills before starting to provide your colleague with advice to use the program.

Correspondence should be sent to P. Marijn Poortvliet, Department of Social Psychology, Tilburg University, Warandelaan 2, PO Box 90153, 5000 LE, Tilburg, The Netherlands. E-mail: p.m. poortvliet@uvt.nl
Although task-related information exchange may take place without any ulterior motive, in this article we argue that people often use information giving to facilitate the attainment of their achievement goals. Achievement goals reflect the aim for an individual's achievement pursuits in a particular situation (Elliot, 2005). Take, for example, a young and high-performing lawyer who wants to exchange information with coworkers to further enhance her job-related performance. With her high task performance in mind, she may decide to share relevant information with a particular associate. This information giving goes hand in hand with the possibility of receiving desired information back, either immediately or at a later time, and thus might eventually contribute to further improving her individual jobrelated skills and enhancing her job performance.

However, when the same lawyer has received feedback indicating that she is performing rather poorly, she may find herself in a difficult position of not being able to give her partner valuable task information, unless she first makes an investment in her task performance. Also problematic may be the situation in which she applies for promotion to a partner position and is faced with a choice between giving or not giving high-quality information to 
a peer who also intends to apply for this job. In this case, sharing information might actually thwart her goal of outperforming the other, which will ultimately reduce her chance of getting the job.

So giving, or not giving, useful task information can be of vital importance for goal attainment and, consequently, information giving can be regarded as hard currency by people who pursue goals in social achievement situations. Feedback is a crucial mechanism that directs people's efforts to the attainment of their personal achievement goals (e.g., DeShon, Kozlowski, Schmidt, Milner, \& Wiechmann, 2004; Senko \& Harackiewicz, 2005). Moreover, performance feedback has been shown to predict not only individuals' subsequent task performance but also their subsequent social exchange behavior (Vigoda-Gadot \& Angert, 2007). For these reasons, we posit that the achievement goals that individuals strive for and the performance feedback they receive during task execution are both important factors in predicting interpersonal exchange behavior.

Until recently, theory and research on achievement goals have predominantly focused on exploring individual cognition, affect, and behavior in relation to task engagement and task performance (for recent reviews, see DeShon \& Gillespie, 2005; Elliot, 2005; Payne, Youngcourt, \& Beaubien, 2007). However, examining the interpersonal effects of achievement goals is important because many achievement situations are typically characterized by the presence of, for example, peers, coworkers, or rivals. People often depend on others to accomplish their goals, most notably by exchanging information. In addition, information exchange has been found to strongly predict performance and task effectiveness in organizations (e.g., Argote \& Epple, 1990; Snyder \& Morris, 1984). Unfortunately, only little is known about the motivational factors that may influence the exchange of information. Recently, research has shown that people with mastery goals are motivated to provide their exchange partners with better taskrelated information than are people with performance goals (Poortvliet, Janssen, Van Yperen, \& Van de Vliert, 2007). The present research aims to extend previous work by arguing and demonstrating that the information giving considerations and behaviors evoked by individuals' mastery versus performance goals are crucially contingent on the valence of the performance feedback that is provided.

\section{ACHIEVEMENT GOALS AND EXCHANGE ORIENTATIONS}

Most attention in the achievement goal tradition has been given to two types of goals: mastery and performance goals. These have typically been portrayed, both implicitly and explicitly, as approach forms of selfregulation. ${ }^{1}$ In that tradition, a mastery goal involves the aim of developing competence and gaining skill, whereas a performance goal reflects the aim of performing better than others (Elliot, 2005; Van Yperen, 2006). These different perspectives on achievement direct mastery goal individuals to predominantly compare their present performance with their previous performances, whereas performance goal individuals tend to compare their performances with those of others. Given this disparity of focus, people who pursue different achievement goals will presumably develop distinct perceptual-cognitive frameworks with which they construe and construct information exchanges with others (Dweck, 1986). Because exchange partners are potential sources of valuable information and at the same time social comparison targets (Darnon, Butera, \& Harackiewicz, 2007), people endorsing different achievement goals can be expected to establish distinct exchange orientations. These orientations will enable them to achieve their achievement goals, that is, improving their own performances for mastery goal individuals, and outperforming others for performance goal individuals. Indeed, previous research has identified two distinct exchange orientations: a reciprocity orientation and an exploitation orientation (Poortvliet et al., 2007).

With a focus on self-improvement, mastery goals tend to lead individuals to perceive exchange partners as their "allies" because exchanging and pooling task-related know-how and skills with others may facilitate attaining the goals of developing personal competence and mastering tasks (Poortvliet et al., 2007). Therefore, when individuals pursue a mastery goal, the reciprocity norm may become salient to them and therefore, they may adopt a reciprocity orientation toward information exchange with others in social achievement situations. The reciprocity norm serves as a mechanism to establish and maintain exchange because it obliges the party that has received a benefit to repay it later (e.g., Bommer, Miles, \& Grover, 2003; Eisenberger, Cotterell, \& Marvel, 1987; Gouldner, 1960). We define reciprocity orientation as the belief that giving valuable information to an exchange partner will lead to receiving good information in return (cf. Poortvliet et al., 2007).

By contrast, from the perspective of individuals pursuing performance goals, exchange partners may be perceived as "rivals" rather than "allies." These kinds of situations in which individuals pursue performance goals are not hypothetical. On the contrary, academic situations in which students receive individual judgments or organizational contexts wherein for instance

\footnotetext{
${ }^{1}$ In this article, we use the terms mastery goals and performance goals for mastery-approach goals and performance-approach goals, respectively.
} 
only one employee has promotion prospects are common. Individuals pursuing performance goals may therefore be tempted to break the reciprocity norm and hence try to exploit others, because sharing know-how and combining skills with someone else is counterproductive if one is striving for superiority over the other. Instead, giving others as little information as possible while strongly profiting from the information others share is a logical strategy when pursuing a performance goal. Performance goal individuals therefore tend to develop an exploitation orientation, defined as the tendency to give others as little valuable information as possible and not wanting others to profit from one's own information.

Prior research has shown that people with mastery goals gave better information to their exchange partners than people with performance goals (Poortvliet et al., 2007). This effect of achievement goals on information giving was indeed mediated differently by the two exchange orientations: relative to performance goals, mastery goals created a stronger reciprocity orientation, whereas relative to mastery goals, performance goals produced a stronger exploitation orientation. The present research aims to refine these previous findings by illuminating the crucial role of performance feedback in this regard. We expected that performance feedback is essential in the processes of information giving because, as the young lawyer exemplifies, the level of individual performance determines the potential to give useful information to others. More specifically, we expected that the effect of achievement goals on information giving would be moderated by performance feedback.

\section{PERFORMANCE FEEDBACK IN MOTIVATED INFORMATION GIVING}

In situations in which tasks are novel and complex and where problem solutions and task outcomes are unknown, such as in project teams or in multidisciplinary work groups, performance feedback is informative as it gives an indication of the level of performance and acquired task proficiency with respect to the task being executed. Individuals with mastery goals are motivated to improve their own performance, whereas performance goal individuals strive to outperform others, so performance feedback is important for individuals with either goal. Also, when people are in the process of carrying out tasks, they often receive and gather feedback on their performance (Sansone, 1986). In fact, performance feedback is ubiquitous, and more important, it directs the efforts and behavior of individuals in achievement situations (Davis, Carson, Ammeter, \& Treadway, 2005; DeShon et al., 2004; VandeWalle, Cron, \& Slocum, 2001). Self-evidently, when such achievement situations involve information exchange, performance feedback provides indications of whether or not one is able to give meaningful information to others.

Recall that in exchange situations individuals with mastery goals tend to develop a strong reciprocity orientation and a weak exploitation orientation relative to performance goal individuals (Poortvliet et al., 2007). From a mastery goal perspective, giving high-quality information is regarded as investing in the other to receive good information in return. However, this is only a direct option for them if they have received positive performance feedback. When an individual with a mastery goal has received negative feedback instead, sharing high-quality information is, by definition, not an option. For this reason, we expected that negative feedback will evoke a tendency among mastery goal individuals to improve their performance before they give task-related information to their exchange partners. Therefore, we expected that, particularly among mastery goal individuals, the valence of performance feedback is a crucial moderator of information-giving behavior.

In contrast, individuals with performance goals are wary that exchange partners might outperform them and therefore take on a relatively strong exploitation orientation and a weak reciprocity orientation. Giving useful information to their exchange partners will obstruct their desire to outperform them, and therefore performance goal individuals are motivated to give information of low quality to their exchange partners (Poortvliet et al., 2007). Accordingly, we expected that individuals with performance goals deliberately modify information to provide poor-quality information to their exchange partners. That is, when performance goal individuals receive positive performance feedback, they do not want to share their task-related information, because this would give their exchange partners valuable indications which task strategies are worthwhile. Also, individuals with performance goals who receive negative performance feedback will likely give modified information about their task performance. Being frank about one's low performance may not be the best option, because this will give the other party at least valuable indications about which task approaches and problem solutions result in poor task performance and thus must not be applied (Ilgen, Fisher, \& Taylor, 1979; Van Yperen, Brenninkmeijer, \& Buunk, 2006). Consequently, before task-related information is shared with others, it will first be modified by individuals who pursue performance goals in order to deceive exchange partners.

\section{OVERVIEW OF EXPERIMENTS}

All in all, we expected that mastery goals motivate people to give their exchange partners high-quality 
information, whereas performance goals would motivate people to provide poor-quality information. In Experiment 1, we tested the basic idea that performance feedback would moderate the effect of achievement goals on information giving. Individuals with mastery goals who received positive performance feedback were expected to give unmodified task-related information to their exchange partners, whereas mastery goal individuals who received negative feedback would try to improve, and thus modify, the information that they share with their exchange partners. In contrast to their mastery goal counterparts, individuals with performance goals were expected to modify the information regardless of the valence of the feedback that they received. Experiment 2 further investigated the motives underlying this expected combined effect of achievement goals and performance feedback. More specifically, we expected that mastery goals would lead, relatively to performance goals, to a stronger reciprocity orientation and a weaker exploitation orientation. Also, we expected that mastery goal individuals would provide better task-related information than performance goals individuals.

\section{EXPERIMENT 1}

In this experiment, we asked participants to work individually on an assignment. After completion of a first task component, we provided them with either positive or negative bogus feedback on their task performance. Then, the participants were asked to give task-related information to their exchange partner. The information they provided could be compared with the information they originally possessed so that we could determine whether the information was, or was not, actively modified.

Because individuals may assume that their exchange partners receive performance feedback as well, in Experiment 1 we also explored the possible effect of performance feedback provided to the exchange partner. Because mastery goal individuals are focused on improving themselves, it could be argued that mastery goals lead to more helpful behavior when one interacts with a competent exchange partner. On the other hand, research shows that mastery goal individuals are willing to cooperate with others regardless of their status (Levy, Kaplan, \& Patrick, 2004), and that mastery goals are positively related to backing up behavior, the provision of task-related effort to others that are apparently failing in their task performance (Porter, 2005). Furthermore, it could be expected that performance goal individuals are motivated to provide poorer information to high performers compared to low-performing others, because competent others are the tougher opponents.
However, with regard to information exchange, a low competent exchange partner could easily turn into a high competent exchange partner upon receiving high-quality information. For these reasons, we had no clear a priori expectations about the effects of the performance level of the exchange partner on information modification.

\section{Method}

\section{Participants and Design}

One hundred ninety-one students (82 men and 109 women $)^{2}$ participated in the experiment and were paid $(€ 7)$ or received partial course credit for their participation. They were randomly assigned to one of the conditions of the 2 (goal: mastery vs. performance) $\times 2$ (performance feedback: positive vs. negative) $\times 2$ (other's performance: great vs. poor) factorial design.

\section{Procedure}

Upon arrival at the laboratory, participants were led to separate cubicles, each of which contained a computer with a monitor and a keyboard. Next to the monitor, participants found pieces of paper and a pencil. Participants were told that the computers were connected to one another and that it was possible to communicate with others by means of the computer network. The computers were used to present the stimulus information and to collect data.

The experiment, lasting a total of $50 \mathrm{~min}$, started off by presenting the winter survival exercise (Johnson \& Johnson, 2000) to the participants. The exercise involved reading a scenario that described the crash landing of a plane in a very cold and desolate area. Both pilots were killed in the crash and the plane was lost. However, the surviving passengers managed to salvage 12 items from the plane (e.g., a hand axe, a compass, a lighter). After reading this scenario, the participants were instructed to think about and write down the possible advantages and disadvantages of each of the 12 items on a form. Then the participants ranked the 12 items in order of their importance for survival on a piece of paper and entered this ranking into the computer.

Next, participants were given bogus feedback on their performance. The participants were told that an ideal ranking existed and that their ranking was compared with this ideal ranking, yielding a score of their performance, with a possible range of 1 to 100 points. Participants received feedback that their score was either

\footnotetext{
${ }^{2}$ In both experiments presented here, gender was proportionally distributed among conditions. Gender had no main or interaction effects on the dependent variables considered in the experiments and was thus dropped from the analyses.
} 
between 75 and 80 points (positive performance feedback) or between 20 and 25 points (negative performance feedback).

After having received performance feedback, participants were informed that another participant had simultaneously carried out this assignment and that they would now exchange rankings of the 12 items with this other person. The participants were told that, to develop a general idea about the performance of the other person, they would receive information about the performance level of this person. Participants read that the other's score was either in the range between 75 and 80 points (great-performing other) or in the range between 20 and 25 points (poor-performing other). In reality, however, the information about the other person was simulated by the computer.

Participants were instructed that they would first give a ranking of the 12 items to the other, then would receive a ranking from the other, after which they would make a final individual ranking. However, the experiment actually stopped after the participants had given their ranking to the other. When participants had been given their instructions, goal manipulation was induced. In line with Van Yperen (2003), the following goals were assigned: "Perform better on your final ranking as compared to your first ranking" (mastery goal) or "Perform better on your final ranking as compared to the other" (performance goal). Next, the participants reflected on the goal that was assigned to them to intensify the achievement goal manipulation. Participants were asked to write down their answers to two questions concerning the thoughts and feelings evoked by the specific goal assigned to them (cf. Poortvliet et al., 2007).

After the procedure was explained, feedback concerning own and other's performance was given, and goal manipulations were induced, the participants were asked to send a ranking to the other using the computer network. The participants had complete freedom as to whether they sent the actual ranking they had drawn up earlier or a different ranking to the other person. After this, the manipulation checks were assessed, the participants were thanked for their participation, and they were thoroughly debriefed.

\section{Measures}

Manipulation checks. Achievement goal manipulation was checked by asking participants to indicate which specific goal had been assigned to them for the exercise. Participants could choose between a mastery goal or a performance goal.

Performance feedback manipulation was checked by asking the participants to indicate, by approximation, the number of points that they received on their first ranking ( 1 to 100 points). The manipulation of performance feedback was further checked by asking participants how high (from 1 [very low] to 7 [very high]) and good (from 1 [very bad] to 7 [very good]) they thought the number of points they received was. These judgments were averaged to form a reliable performance feedback judgment index $(\alpha=.98)$.

Manipulation of other's performance was also checked by asking the participants to indicate, by approximation, the number of points that the other received (1-100 points). The manipulation of other's performance was further checked by asking participants how high (from 1 [very low] to 7 [very high]) and good (from 1 [very bad] to 7 [very good]) they thought the number of points the other received was. These judgments were also averaged to form a reliable other's performance judgment index $(\alpha=.96)$.

Information modification. Was assessed by computing the Spearman rank order correlation between the initial ranking the participants produced and the ranking they gave to the other. This measure enabled us to detect modifications between the initial ranking the participants made and the ranking that they made available to the other. A correlation of 1 indicated that there was no difference between the initial ranking and the ranking that the participants gave to the other. The lower the correlation, the more modifications participants made to the ranking they gave to the other, compared to their initial ranking. Because correlations typically are not normally distributed, the Spearman rank order correlation was standardized by means of the Fisher $r$-to- $z$ transformation.

\section{Results}

\section{Manipulation Checks}

A chi-square test, comparing the observed frequencies of cases with the actual (or expected) frequencies, revealed that the goal manipulation was successful, $\chi^{2}(1$, $N=191)=127.74, p<.001$. The assigned achievement goal was correctly recalled by $90.6 \%$ of participants. ${ }^{3}$

A $2 \times 2 \times 2$ multivariate analysis of variance (MANOVA) on the number of points received and the performance feedback judgment index indicated the expected main effect of the performance feedback manipulation at both the multivariate level and the univariate levels: multivariate $F(2,182)=1685.25, p<.001$; for the number of points received $F(1,183)=3367.32, p<.001$; for the performance feedback judgment index

\footnotetext{
${ }^{3}$ In both experiments, we also did additional analyses including only those participants who correctly indicated the assigned goal. This yielded similar results.
} 
TABLE 1

Means and Standard Deviations of Information Modification as a Function of Achievement Goal and Performance Feedback (Experiment 1)

Goal

Mastery Performance

\begin{tabular}{lcccccc}
\cline { 2 - 6 } Performance Feedback & $M r$ & $M z$ & $S D z$ & $M r$ & $M z$ & $S D z$ \\
\hline Positive & 0.99 & $9.12_{\mathrm{a}}$ & 1.69 & 0.83 & $6.01_{\mathrm{b}}$ & 4.23 \\
Negative & 0.85 & $6.01_{\mathrm{b}}$ & 4.19 & 0.82 & $6.26_{\mathrm{b}}$ & 4.27 \\
\hline
\end{tabular}

Note. $M r=$ mean Spearman correlation; $M z=$ mean Fisher $z$ value; $S D z=$ standard deviation of Fisher $z$ value. Higher means indicate information giving with fewer modifications. Means that do not share subscripts differ significantly at $p<.05$.

$F(1,183)=990.70, p<.001$. As intended, participants who had received positive performance feedback reported having received more points $(M=76.02, S D=2.19)$ than those who had received negative performance feedback $(M=25.30, S D=8.52)$. Next, as intended, analyses on the performance feedback judgment index showed that participants who had received positive performance feedback reported having a better performance $(M=5.66$, $S D=.66)$ than those who had received negative performance feedback $(M=2.20, S D=.84)$.

A $2 \times 2 \times 2$ MANOVA on the number of points the other received and the other's performance judgment index indicated the expected main effect of the other's performance manipulation at both the multivariate level and the univariate levels: multivariate, $F(2,182)=$ $1788.44, p<.001$; for the number of points the other received, $F(1,183)=3568.29, p<.001$; for the other's performance judgment index, $F(1,183)=905.17, p<.001$. As intended, participants who had received information about the other having a great performance reported that the other received more points $(M=74.76, S D=5.91)$ than those who had received information about the other having a poor performance $(M=24.56, S D=6.01)$. Next, as intended, participants who were informed that the other had a great performance reported that the other had a better performance $(M=5.59, S D=0.70)$ than those who were informed about the other having a poor performance $(M=2.37, S D=0.77)$.

\section{Information Modification}

The means and standard deviations of the dependent variable of information modification are displayed in Table $1{ }^{4}$ A $2 \times 2 \times 2$ analysis of variance (ANOVA) on this variable yielded a main effect of achievement goals, $F(1,183)=6.81, p=.01, \eta_{p}^{2}=.04$, and a main effect of performance feedback, $F(1,183)=7.01$, $p=.01, \eta_{p}^{2}=.04$. These main effects were qualified by an interaction effect between achievement goal and

\footnotetext{
${ }^{4}$ For ease of interpretation, we also report the unstandardized correlations in Tables 1 and 2. However, all reported tests were performed on the standardized $z$ values.
}

performance feedback, $F(1,183)=9.51, p<.01, \eta_{p}^{2}=$ .05 . There was no main effect of other's performance, $F(1,183)=1.12, n s, \eta_{p}^{2}=.01$, no two-way interaction between achievement goal and other's performance, $F(1,183)=1.61, n s, \eta_{p}^{2}=.01$, nor between performance feedback and other's performance, $F(1,183)=.97, n s$, $\eta_{p}^{2}=.01$, nor a three-way interaction between the three independent variables, $F(1,183)=.05, n s, \eta_{p}^{2}=.00$.

To interpret the effects of achievement goal and performance feedback, we employed contrast analysis (Furr \& Rosenthal, 2003; Rosnow \& Rosenthal, 1995). In line with our expectation, this contrast analysis revealed that the mastery goal-positive performance feedback manipulation resulted in fewer modifications to the ranking given to the other than the mastery goal-negative performance feedback and both performance goal manipulations, $t(183)=4.83, p<.001$. Two additional contrasts indicated that the mastery goalnegative performance feedback condition did not differ from both performance goal conditions, $t(183)=.21$, $n s$, nor did a contrast that tested the difference between the two performance goal conditions turn out to be significant, $t(183)=.31, n s$.

\section{EXPERIMENT 2}

The results of Experiment 1 showed that achievement goals and performance feedback each had an independent effect on information giving behavior. Follow-up analyses revealed that mastery goal individuals who received positive performance feedback, gave less modified information about their first task performance to their exchange partner, relative to mastery goal individuals who received negative performance feedback or performance goal individuals (who received either positive or negative performance feedback).

In Experiment 1, we tested for the possible influence of the level of the other's performance. However, we did not find a main effect nor interaction effects of this variable on information modification. Therefore, in Experiment 2, we focused exclusively on the combined effect of achievement goals and the level of 
the actor's performance feedback on information giving behavior.

Another aspect of the procedure in Experiment 1 also deserves attention. The achievement goal manipulations were checked by asking the participants to indicate which specific goal was assigned to them. To check whether the participants in the two different goal conditions were actually in the intended psychological state, in Experiment 2 we also asked participants to indicate how important the two possible achievement goals were to them during task performance.

The goal of Experiment 2 was to investigate the assumed motives that may underlie the patterns of information giving behavior observed in Experiment 1: Individuals with mastery goals and negative performance feedback and individuals with performance goals and negative or positive performance feedback alike modified their information to a greater extent than individuals with mastery goals who received positive performance feedback. Our basic assumption was that this observed effect with regard to information giving behavior was caused by the strength of specific exchange orientations that participants adopted. Therefore, in Experiment 2 we tested our expectations that mastery goals would lead, relatively to performance goals, to a stronger reciprocity orientation and a weaker exploitation orientation. Of course, the observed modification of information may have two reasons: One modifies it to make it more useful, or one modifies it in an effort to make it less useful or even worthless. In order to gain further insight into the reason of why participants modified the information that they provided to their exchange partners, we therefore assessed the perceived quality of the given information.

\section{Method}

\section{Participants and Design}

One hundred students (46 men, 54 women) participated in the experiment and were paid (€7) or received partial course credit for their participation. They were randomly assigned to one of the conditions of the 2 (goal: mastery vs. performance) $\times 2$ (performance feedback: positive vs. negative) factorial design. The design was balanced, with 25 participants taking part in each of the conditions.

\section{Procedure}

The experimental procedure was identical to that of Experiment 1, except for the below mentioned points. After making a ranking on the winter survival exercise and entering this ranking in the computer, the participants were told that an ideal ranking existed, and that their ranking was compared with this ideal ranking, yielding a score of their performance with a possible range of 1 to 100 points. Participants received task-feedback that their score was either 77 points (positive performance feedback) or 23 points (negative performance feedback). The participants did not receive information about the performance of the other participant. After the procedure had been outlined to the participants, the achievement goal and performance feedback manipulations were induced, followed by an assessment of the dependent variables and manipulation checks. At the end of the study, the participants were thanked for their participation and were thoroughly debriefed.

\section{Measures}

Manipulation checks. In correspondence with Experiment 1, the achievement goal manipulation was checked by asking participants to indicate which specific goal had been assigned to them. In addition, we now also measured the strength of goal manipulation by asking participants to indicate the extent to which it was important for them to perform better on their final ranking than on their first ranking (from 1 [not important at all] to 7 [very important]; mastery goal strength), and the extent to which it was important to them to perform better on their final ranking than the other participant (from 1 [not important at all] to 7 [very important]; performance goal strength).

The performance feedback manipulation was checked by asking participants to indicate how many points they had received on their first ranking (1-100 points). The manipulation of performance feedback was further checked by asking participants how high (from 1 [very low] to 7 [very high]) and good (from 1 [very bad] to 7 [very good]) they thought the number of points they had received was. These judgments were averaged to form a reliable performance feedback judgment index $(\alpha=.98)$.

Information modification. Was assessed in the same way as in Experiment 1.

Reciprocity orientation. Was assessed with the following five items $(\alpha=.75)$ : "I am glad to help the other, because then I will surely receive a good deal of useful information in return"; "It would be naïve to expect the other to help you, simply because you help this person" (reverse scored); "I have low confidence that I will receive much good information from the other" (reverse scored); "I assume that the other will help me well"; and "I have helped the other and now I expect the other to do the same to me." Each item was accompanied by a scale ranging from 1 [strongly disagree] to 7 [strongly agree]. 
Exploitation orientation. ${ }^{5}$ Was assessed with the following five items ${ }^{6}(\alpha=.84)$ : "I hope the other will not profit too much from my information"; "I hope that my information is useful for the other" (reverse scored); "I don't care when the other receives poor information from me"; "I'd be glad if the other could use my information" (reverse scored); and "I would rather give no information at all." Each item was accompanied by a scale ranging from 1 [strongly disagree] to 7 [strongly agree].

Perceived quality of information giving. This variable was assessed with two items $(r=.73, \alpha=.84)$ : "I think that I have given useful information to the other" and "the other can profit from the information I provided." Each item was accompanied by a scale ranging from 1 [strongly disagree] to 7 [strongly agree].

\section{Results}

\section{Manipulation Checks}

A chi-square test, comparing the observed frequencies of cases with the actual (or expected) frequencies, revealed that the goal manipulation was successful, $\chi^{2}(1, N=100)=88.68, p<.001$. The assigned achievement goal was correctly recalled by $97.0 \%$ of participants. Next, a $2 \times 2$ MANOVA on the strength of goal manipulation measures yielded a main effect only of achievement goal at both the multivariate level and the univariate levels: multivariate, $F(2,95)=10.92$, $p<.001$; for strength of mastery goal, $F(1,96)=4.25$,

\footnotetext{
${ }^{5}$ In exchange situations, people differ in the extent to which they have concern for others and for themselves (Van de Vliert, 1999). As the exploitation orientation measure shows, people with performance goals have a lower concern for others than people with mastery goals. However, we do not expect that performance goals lead to a stronger concern for the self than do mastery goals. It is central to the concept of mastery goals to improve their ability, whereas performance goals lead people to try to prove their ability, so it may be expected that both goals are connected to a high concern for self. Therefore, a concern for self scale was also administered in Experiment 2 (six items, $\alpha=.74$; illustrative examples are "I hope to profit from the other's information" and "I'm not interested whether the other provides me with good information," reverse scored). The results show that the performance goal condition does not differ from the mastery goal condition on this measure, $F(1,96)=.08, p=.78$. Measuring exploitation orientation by including both elements of concern for the self and concern for the other could lead to unwanted entanglement of these two dimensions. For this reason, and also because of possible evaluation apprehension problems (Rosenberg, 1965), we opted for construction of a measure of exploitation that exclusively focused on the concern-for-other aspect of exploitation.

${ }^{6}$ The correlation between the Reciprocity Orientation and Exploitation Orientation subscales is -.59 . A principal component analysis with varimax rotation indicated that the two different exchange orientations loaded on two separate factors. All items loaded above .60 on their primary factor, with the exception of one loading of .53 on the primary factor.
}

$p=.04$; for strength of performance goal, $F(1,96)=$ 12.91, $p<.001$. As intended, participants who were in the mastery condition reported having a stronger mastery goal $(M=5.62, S D=1.01)$ than participants in the performance condition $(M=5.12, S D=1.37)$. Finally, and as intended, participants who were in the performance condition reported having a stronger performance goal $(M=4.60, S D=1.54)$ than participants in the mastery condition $(M=3.42, S D=1.72)$.

A $2 \times 2$ MANOVA on the number of points received and the performance feedback judgment index indicated the expected main effect of the performance feedback manipulation at both the multivariate level and the univariate levels: multivariate, $F(2,95)=4483.29, p<.001$; for the number of points received, $F(1,96)=8421.20$, $p<.001$; for the performance feedback judgment index, $F(1,96)=765.03, p<.001$. As intended, participants who had received positive performance feedback reported having received more points $(M=76.98$, $S D=1.55)$ and having a better performance $(M=5.61$, $S D=0.65)$ than those who had received negative performance feedback $(M=23.04, S D=3.82$, and $M=1.76$, $S D=0.74$, respectively).

\section{Information Modification}

The main dependent variable assessed the information participants gave to the other (information modification). The means and standard deviations of this variable are displayed in Table 2 . A $2 \times 2$ ANOVA on this variable yielded a main effect of performance feedback, $F(1,96)=4.82, p=.03, \eta_{p}^{2}=.05$, no main effect of achievement goals, $F(1,96)=1.87, n s, \eta_{p}^{2}=.02$, and no significant interaction effect, $F(1,96)=.31, n s, \eta_{p}^{2}=.00$.

As in Experiment 1, we employed contrast analyses to test our expectations. As expected, the first contrast revealed that the mastery goal-positive performance feedback manipulation produced fewer modifications to the information given to the other than the mastery

TABLE 2

Means and Standard Deviations of Information Modification as a Function of Achievement Goal and Performance Feedback (Experiment 2)

\begin{tabular}{lcccccc}
\hline & \multicolumn{6}{c}{ Moal } \\
& \multicolumn{7}{c}{ Mastery Performance } \\
\cline { 2 - 7 } Performance Feedback & $M r$ & $M z$ & $S D z$ & $M r$ & $M z$ & $S D z$ \\
\hline Positive & 0.97 & $8.28_{\mathrm{a}}$ & 3.01 & 0.83 & $6.71_{\mathrm{b}}$ & 4.25 \\
Negative & 0.83 & $6.04_{\mathrm{b}}$ & 4.41 & 0.79 & $5.38_{\mathrm{b}}$ & 4.46 \\
\hline
\end{tabular}

Note. $M r=$ mean Spearman correlation; $M z=$ mean Fisher $z$ value; $S D z=$ standard deviation of Fisher $z$ value. Higher means indicate information giving with fewer modifications. Means that do not share subscripts differ significantly at $p<.05$. 
goal-negative performance feedback manipulation and both performance goal manipulations, $t(96)=2.38$, $p=.02$. The second contrast indicated that the mastery goal-negative performance feedback condition did not differ from both performance goal conditions, $t(96)=.01, n s$, nor did the contrast that tested the difference between the two performance goal conditions turn out to be significant, $t(96)=1.16, n s$, thereby exactly replicating the pattern found in Experiment 1.

\section{Reciprocity Orientation}

A $2 \times 2$ ANOVA on the reciprocity orientation scale yielded a main effect of achievement goal, $F(1$, $96)=6.28, p=.01, \eta_{\mathrm{p}^{2}}=.06$, but no main effect of performance feedback, $F(1,96)=1.45, n s, \eta_{\mathrm{p}^{2}}=.01$, nor an interaction effect, $F(1,96)=.88, n s, \eta_{\mathrm{p}^{2}}=.01$. Participants in the mastery goal condition had a stronger reciprocity orientation $(M=4.43, S D=0.86)$ than participants in the performance condition $(M=3.90$, $S D=1.21)$.

\section{Exploitation Orientation}

A $2 \times 2$ ANOVA on the exploitation orientation scale showed a main effect of achievement goal, $F(1$, 96) $=9.05, p<.01, \eta_{p}^{2}=.09$, no main effect of performance feedback, $F(1,96)=.50, n s, \eta_{p}^{2}=.01$, nor a significant interaction effect, $F(1,96)=2.17, n s, \eta_{p}^{2}=.02$. Participants in the performance goal condition had a stronger exploitation orientation $(M=3.26, S D=1.48)$ than participants in the mastery goal condition $(M=2.51, S D=0.98)$.

\section{Perceived Quality of Information Giving}

A $2 \times 2$ ANOVA on the perceived quality of information giving scale yielded a main effect of achievement goals, $F(1,96)=4.96, p=.03, \eta_{p}^{2}=.05$, no main effect of performance feedback, $F(1,96)=.83, n s, \eta_{p}^{2}=.01$, and no significant interaction effect, $F(1,96)=1.82$, $n s$, $\eta_{p}^{2}=.02$. Participants with a mastery goal reported to have given better information to the other $(M=4.86$, $S D=1.25)$ than participants with a performance goal $(M=4.25, S D=1.49)$. More important, an additional contrast showed that the mastery goal-negative performance feedback condition significantly differed from both performance goal conditions, $t(96)=2.00, p<.05$.

\section{GENERAL DISCUSSION}

The results of the current investigation provide support for the novel idea that performance feedback moderates the effect of achievement goals on information giving, as was reflected by the extent to which individuals modified task-related information that they provided to exchange partners. $^{7}$ Experiment 2 showed that mastery goals evoke a reciprocity orientation, whereas performance goals elicit an exploitation orientation when it comes to giving task-related information to an exchange partner. Furthermore, it was shown that mastery goal individuals who received negative feedback explicitly reported to have given better information than performance goal individuals with positive or negative feedback. This gives ground for the assumption that the former modify their information for benevolent reasons, whereas the latter modify their information to sabotage their exchange partner's task performance.

Experiment 1 showed that the exchange partner's performance level did not play a part in this regard, whereas Experiment 2 generalized the effects to an exchange context in which no performance information about the other is available. Apparently, mastery goal individuals show benevolent behavior both when they interact with a high performing other and with an inapt exchange partner. This is in line with the finding that mastery goals predict backing up behavior (Porter, 2005). Also, the information giving behavior of performance goal individuals was unaffected by the feedback of their exchange partner. Consequently, both highand low-performing others are taken serious as adversaries by performance-driven individuals, because both receive poor information.

\section{Theoretical Implications}

Earlier research showed that mastery goals lead to a reciprocity orientation and performance goals to an exploitation orientation, and that relative to mastery goal individuals, people with performance goals give poor information to their exchange partners (Poortvliet et al., 2007). The current research expands on these findings by focusing on the critical part that performance feedback plays in this regard. The moderating role of performance feedback provides strong support for the idea that exchange orientations shape information giving behavior. Namely, individuals with a mastery goal and positive performance feedback give relatively unmodified information about their initial task

\footnotetext{
${ }^{7} \mathrm{We}$ also looked at how many participants in each of the conditions modified the information that they gave to their exchange partners. In Experiment 1 and 2 combined, in the mastery goal-positive feedback condition 7 of 73 participants $(9.6 \%)$ provided information that was modified to some extent. In comparison, in the other three conditions the percentage ranged from $38.9 \%$ to $41.9 \%$. So, these figures yield the same pattern that was found by looking at the rank order correlations: relative to the other three conditions, mastery goal participants who received positive feedback did not tend to modify their original information to the same extent.
} 
performance to their exchange partners, but upon receiving negative performance feedback they modified information to increase the potential value of it for their exchange partners.

In this regard, it could be argued that individuals with mastery goals wish to share all kinds of performance information, because just like positive feedback gives indications about what to do, negative feedback informs the recipient about what not to do (Ilgen et al., 1979; Van Yperen et al., 2006). However, in the present experimental procedure participants had no possibility to add any comments to the information that they gave to the other, so they could not reveal their intentions and motives to their exchange partner. So, even though people with mastery goals may find themselves in a difficult situation when they receive negative performance feedback, they seem nevertheless to make efforts to provide their exchange partner with high-quality information by modifying their information, and thus act in line with their reciprocity orientation. Apparently, the reciprocity principle motivates individuals to develop a dual concern: a concern for self-interests and a concern for the interests of others. The self-interest involved is actually the goal, namely, improving performance on a given task, and the concern for the interests of the exchange partner is the means, namely, by giving high-quality information to the exchange partner to make him or her willing to respond in a similar way (Yang, Van de Vliert, Shi, \& Huang, 2008).

In a different way, individuals with performance goals also actively put effort into the information that they give to their exchange partner, but most probably they do so to deceive the other. Thus, exchange partners who receive information from people pursuing performance goals benefit much less than they would if they interacted with mastery driven individuals. The results suggest that performance goals motivate people to give information of poor quality to their exchange partners. Individuals with performance goals acted from an exploitation orientation, which allows us to assume that they actively tried to give their exchange partners low-quality information. In this regard, it could be argued that when one is trying to sabotage exchange partners' task performance, it is wise to give much poorer rankings than the participants in the current investigation did. However, if a performance goal individual tries to sabotage the task performance of their exchange partner, such an act is likely to be most effective when the exchange partner actually decides to utilize the received information. In that sense, giving moderately poor information rather than blatantly bad information may be a much more effective strategy to follow, because in the former case the poor quality of the information may stay 'under the radar' and in turn be adopted. Future research should therefore further investigate whether performance goal individuals hold such tactical deception attitudes.

The results of both experiments show that performance goal participants with negative feedback modify the information they share. However, it could also be argued that when you aim to sabotage another's task performance and have just received negative feedback, the best strategy would be to give unmodified information because this is certainly less useful or even worthless information. However, the results show that in this case performance goal individuals still modify their information, so they are reluctant to share their original information even though they know that this information is in fact poor. We reasoned that providing unmodified information about one's low performance may give the other party valuable indications about which task approaches and problem solutions are inappropriate and must not be applied. Because performance goal participants with negative feedback actually report to have provided relatively poor information, they apparently feel confident that their information modification does not put them at the risk of providing improved rather than poor information.

\section{Practical Implications}

From the perspective of companies, information giving is vital for innovation and knowledge creation (Starbuck, 1997), and consequently, for the competitive strength of the organization as a whole (Argote \& Ingram, 2000). Therefore, it is critical to understand the psychological processes that are involved when individuals have to exchange information to perform their tasks. Precisely in those domains where companies have to deal with new and complex situations, the use of work teams is common (Howard, 1995). These teams consist of members who have to develop task-related skills to attain desirable performance outcomes. The positive potentials in the cognitive diversity of people with different performance levels can only effectively be harvested when suitable knowledge is actually exchanged.

People with mastery goals seem to intend to provide useful information to their exchange partners, even when they face negative performance feedback. In contrast, performance goals appear to hinder exchange processes. Given the vital role of information for organizations, it has been suggested that exchanges should be encouraged between people by formalizing the transfer of information. This can be achieved, for example, by creating environments and occasions where employees can interact with each other. However, such interventions offer no guarantee that valuable information is actually exchanged. The exchange behavior displayed by individuals with performance goals might interfere with the potential positive outcomes that typically result 
from information exchange. Our preliminary inference from the current investigation is that the promotion of mastery goals within employees may be a very promising avenue to facilitate exchanges of high quality information.

This recommendation is consistent with earlier findings that mastery goals were especially beneficial for task effectiveness in social contexts (e.g., Bereby-Meyer, Moran, \& Unger-Aviram, 2004; Porter, 2005; Utman, 1997). Mastery goals may also be more beneficial for long-term relationships, because people who endorse these goals are motivated to give high-quality information to their exchange partners (cf. Chiaburu, Marinova, \& Lim, 2007; Janssen \& Van Yperen, 2004). This cooperative behavior will potentially promote these exchange partners' performance, and eventually, through the principle of reciprocity, also benefit the actor who displayed this behavior in the first place (Bommer et al., 2003). Over time, this positive spiral of reciprocity may benefit organizations as a whole (Nonaka \& Takeuchi, 1995). The current investigation showed that individuals with mastery goals, upon receiving negative performance feedback, reacted proactively by investing in their performance before they shared information with others (cf. Nichols, Whelan, \& Meyers, 1991). Future research could address the possible effectiveness of negative performance feedback interventions within mastery goal individuals on information-giving behavior.

In contrast to mastery goals, we conclude that performance goals do not seem to be beneficial for the quality of working relationships, at least in situations where negative outcome interdependence exists between coworkers (Johnson \& Johnson, 1989). However, when people repeatedly give information of low quality to their exchange partners, they are not likely to be very popular. Therefore, in ongoing relationships, coworkers will not likely put up with this kind of behavior (e.g., Kurzban, McCabe, Smith, \& Wilson, 2001). There is also evidence that people who behave deceptively will eventually start to believe that others are dishonest as well (Sagarin, Rhoads, \& Cialdini, 1998). So, the shortterm benefits that people who pursue performance goals reap when trying to establish superiority over their coworkers are most probably outweighed by their long-term costs (cf. Crocker \& Park, 2004). It should be noted that the present investigation focused on dyads, and therefore one should be careful when generalizing the results of this study to larger groups or teams. Indeed, Tauer and Harackiewicz (2004) showed that teams tend to share similar goals for success. A crucial moderator in this regard may be whether performance goal individuals perceive their team members to share a common performance goal. If they do share such a goal, then the potential competitive consequences of performance goals within teams are likely tempered. However, if performance goal individuals do not share common goals, like in the present research, then performance goals may breed strong intradyadic competition.

\section{Limitations and Strengths}

We did not study ongoing relationships, characterized by iterative exchanges between individuals who share a history, but instead used a procedure in which participants interacted anonymously with another person. In our investigation, we focused on the initial and spontaneous reactions and behaviors people display in a dyadic setting as a consequence of their achievement goals and the performance feedback that they receive. It may be assumed that the behaviors displayed by the participants directly reflected considerations that were evoked by their goal focus (Cotterell, Eisenberger, \& Speicher, 1992). Further field research needs to be conducted to investigate whether the present findings have external validity.

Another aspect of the procedure needs to be addressed as well, because in the two reported experiments participants were not free to exchange information; they simply had to. Although we recognize this potential limitation, we posit that in a large variety of contexts people are not free to choose whether they want to give information to others. For example, in organizations people are often required to provide their coworkers with information simply because this is a formal job requirement. A remaining issue of great relevance for organizational scholars therefore is the impact of having or not having a voluntary choice to exchange with others.

With regard to the experimental design, it should be noted that in the present study no control condition was included. Of course, such a baseline condition would provide valuable information about which specific goal drives the observed effects. Earlier work showed that a mastery goal condition resulted in comparable benevolent information giving behavior compared to a no-goal condition (Poortvliet et al., 2007). However, in that particular study a difference was found between the mastery goal condition and the no-goal condition with regard to the underlying psychological mechanisms. Specifically, mediation analyses revealed that the effect of the performance goal condition on the information giving measure was mediated by reciprocity orientation and exploitation orientation, but only relative to the mastery goal condition (and not relative to the no-goal control condition). Apparently, with regard to information giving behavior, people typically follow the norm of reciprocity (Gouldner, 1960). A performance goal motivates individuals to breach the reciprocity norm, whereas a mastery goal reinforces this norm. 
A particular strength of the current research is the type of measures collected. Although the importance of behavioral measures is recognized in social and organizational psychological research, few studies actually report such hard data (Jones, 1998). Rather than reporting intentions or self-report measures, in the present investigation we focused on genuine information sharing behavior. As in studies on cheating and dishonesty (e.g., Steinel \& De Dreu, 2004), it is not unthinkable that information giving is subject to socially desirable answer tendencies. With this in mind, the winter survival exercise provided a straightforward test of our expectations and served as an unobtrusive measurement instrument to examine the effects of mastery and performance goals in combination with performance feedback on information giving behavior.

\section{CONCLUSION}

Performance feedback moderates the effect of achievement goals on information giving behavior. The present research shows that individuals use the feedback information that they receive during task performance when they engage in information exchange. In particular, this investigation showed that performance goal individuals do not want to share valuable information and they consequently choose to give modified information to their exchange partners regardless of their performance feedback. In contrast, mastery goal individuals are motivated to provide valuable information to their exchange partners and the performance feedback that they receive gives directions for them when they share information with an exchange partner. So upon receiving positive performance feedback they give relatively unmodified information, whereas negative feedback motivates them to first invest in their task performance before they share information with exchange partners.

\section{ACKNOWLEDGMENTS}

We thank Monica Blaga, Joris Lammers, Marjette Slijkhuis, and Sija Speelman for their help with data collection.

\section{REFERENCES}

Argote, L., \& Epple, D. (1990). Learning curves in manufacturing. Science, 247, 920-924.

Argote, L., \& Ingram, P. (2000). Knowledge transfer: A basis for competitive advantage in firms. Organizational Behavior and Human Decision Processes, 82, 150-169.

Bereby-Meyer, Y., Moran, S., \& Unger-Aviram, E. (2004). When performance goals deter performance: Transfer of skills in integrative negotiations. Organizational Behavior and Human Decision Processes, 93, 142-154.

Bommer, W. H., Miles, E. W., \& Grover, S. L. (2003). Does one turn deserve another? Coworker influences on employee citizenship. Journal of Organizational Behavior, 24, 181-196.

Chiaburu, D. S., Marinova, S. V., \& Lim, A. S. (2007). Helping and proactive extra-role behaviors: The influence of motives, goal orientation, and social context. Personality and Individual Differences, 43, 2282-2293.

Cotterell, N., Eisenberger, R., \& Speicher, H. (1992). Inhibiting effects of reciprocation wariness on interpersonal relationships. Journal of Personality and Social Psychology, 62, 658-668.

Crocker, J., \& Park, L. E. (2004). The costly pursuit of self-esteem. Psychological Bulletin, 130, 392-414.

Darnon, C., Butera, F., \& Harackiewicz, J. M. (2007). Achievement goals in social interactions: Learning with mastery vs. performance goals. Motivation and Emotion, 31, 61-70.

Davis, W. D., Carson, C. M., Ammeter, A. P., \& Treadway, D. C. (2005). The interactive effects of goal orientation and feedback specificity on task performance. Human Performance, 18, 409-426.

DeShon, R. P., \& Gillespie, J. Z. (2005). A motivated action theory account of goal orientation. Journal of Applied Psychology, 90, 1096-1127.

DeShon, R. P., Kozlowski, S. W. J., Schmidt, A. M., Milner, K. R., \& Wiechmann, D. (2004). A multiple-goal, multilevel model of feedback effects on the regulation of individual and team performance. Journal of Applied Psychology, 89, 1035-1056.

Dweck, C. S. (1986). Motivational processes affecting learning. American Psychologist, 41, 1040-1048.

Eisenberger, R., Cotterell, N., \& Marvel, J. (1987). Reciprocation ideology. Journal of Personality and Social Psychology, 53, 743-750.

Elliot, A. J. 2005. A conceptual history of the achievement goal construct. In A. J. Elliot \& C. S. Dweck (Eds.), Handbook of competence and motivation (pp. 52-72). New York: Guilford.

Furr, R. M., \& Rosenthal, R. (2003). Repeated-measures contrasts for "multiple-pattern" hypotheses. Psychological Methods, 8, 275-293.

Gouldner, A. W. (1960). The norm of reciprocity: A preliminary statement. American Sociological Review, 25, 161-178.

Howard, A. (1995). The changing nature of work. San Francisco: Jossey-Bass.

Ilgen, D. R., Fisher, C. D., \& Taylor, M. S. (1979). Consequences of individual feedback on behavior in organizations. Journal of Applied Psychology, 64, 349-371.

Janssen, O., \& Van Yperen, N. W. (2004). Employees' goal orientations, the quality of leader-member exchange, and the outcomes of job performance and job satisfaction. Academy of Management Journal, 47, 368-384.

Johnson, D. W., \& Johnson, F. P. (2000). Joining together: Group theory and group skills (7th ed.). Boston: Allyn \& Bacon.

Johnson, D. W., \& Johnson, R. T. (1989). Cooperation and competition: Theory and research. Edina, MN: Interactive Book Company.

Jones, E. E. 1998. Major developments in five decades of social psychology. In D. Gilbert, S. T. Fiske, \& G. Lindzey (Eds.), The handbook of social psychology (4th ed., pp. 3-57). Boston: McGraw-Hill.

Kurzban, R., McCabe, K., Smith, V. L., \& Wilson, B. J. (2001). Incremental commitment and reciprocity in a real-time public goods game. Personality and Social Psychology Bulletin, 27, 1662-1673.

Levy, I., Kaplan, A., \& Patrick, H. (2004). Early adolescents' achievement goals, social status, and attitudes towards cooperation with peers. Social Psychology of Education, 7, 127-159.

Nichols, A. L., Whelan, J. P., \& Meyers, A. W. (1991). The effects of children's goal structures and performance feedback on mood, task choice, and task persistence. Behavioral Therapy, 22, 491-503. 
Nonaka, I., \& Takeuchi, H. (1995). The knowledge creating company: How Japanese companies create the dynamics of innovation. New York: Oxford University Press.

Payne, S. C., Youngcourt, S. S., \& Beaubien, J. M. (2007). A meta-analytic examination of the goal orientation nomological net. Journal of Applied Psychology, 92, 128-150.

Poortvliet, P. M., Janssen, O., Van Yperen, N. W., \& Van de Vliert, E. (2007). Achievement goals and interpersonal behavior: How mastery and performance goals shape information exchange. Personality and Social Psychology Bulletin, 33, 1435-1447.

Porter, C. O. L. H. (2005). Goal orientation: Effects on backing up behavior, performance, efficacy, and commitment in teams. Journal of Applied Psychology, 90, 811-818.

Rosenberg, M. J. (1965). When dissonance fails: On eliminating evaluation apprehension from attitude measurement. Journal of Personality and Social Psychology, 1, 28-42.

Rosnow, R. L., \& Rosenthal, R. (1995). "Some things you learn aren't so": Cohen's paradox, Asch's paradigm, and the interpretation of interaction. Psychological Science, 6, 3-9.

Sagarin, B. J., Rhoads, K. L., \& Cialdini, R. B. (1998). Deceiver's distrust: Denigration as a consequence of undiscovered deception. Personality and Social Psychology Bulletin, 24, 1167-1176.

Sansone, C. (1986). A question of competence: The effects of competence and task-feedback on intrinsic interest. Journal of Personality and Social Psychology, 51, 918-931.

Senko, C., \& Harackiewicz, J. M. (2005). Regulation of achievement goals: The role of competence feedback. Journal of Educational Psychology, 97, 320-336.

Snyder, R. A., \& Morris, J. H. (1984). Organizational communication and performance. Journal of Applied Psychology, 69, 461-465.

Starbuck, W. H. (1997). Learning by knowledge-intensive firms. In L. Prusak (Ed.), Knowledge in organizations (pp. 147-175). Boston: Butterworth-Heinemann.
Steinel, W., \& De Dreu, K. W. (2004). Social motives and strategic misrepresentation in social decision making. Journal of Personality and Social Psychology, 86, 419-434.

Tauer, J. M., \& Harackiewicz, J. M. (2004). The effects of cooperation and competition on intrinsic motivation and performance. Journal of Personality and Social Psychology, 86, 849-861.

Utman, C. H. (1997). Performance effects of motivational state: A meta-analysis. Personality and Social Psychology Review, 1, 170-182.

Van de Vliert, E. (1999). Cooperation and competition as partners. In W. Stroebe \& M. Hewstone (Eds.), European Review of Social Psychology (pp. 231-257). Chichester, UK: Wiley.

VandeWalle, D., Cron, W. L., \& Slocum, J. W. (2001). The role of goal orientation following performance feedback. Journal of Applied Psychology, 86, 629-640.

Van Yperen, N. W. (2003). Task interest and actual performance: The moderating effects of assigned and adopted purpose goals. Journal of Personality and Social Psychology, 85, 1006-1015.

Van Yperen, N. W. (2006). A novel approach to assessing achievement goals in the context of the $2 \times 2$ framework: Identifying distinct profiles of individuals with different dominant achievement goals. Personality and Social Psychology Bulletin, 32, 1432-1445.

Van Yperen, N. W., Brenninkmeijer, V., \& Buunk, A. P. (2006). People's responses to upward and downward social comparisons: The role of the individual's effort-performance expectancy. British Journal of Social Psychology, 45, 519-533.

Vigoda-Gadot, E., \& Angert, L. (2007). Goal setting theory, job feedback, and OCB: Lessons from a longitudinal study. Basic and Applied Social Psychology, 29, 119-128.

Yang, H., Van de Vliert, E., Shi, K., \& Huang, X. (2008). Whose side are you on? Relational-norms based siding among Dutch and Chinese employees. Journal of Occupational and Organizational Psychology, 81, 713-731. 